Article

\title{
An Experimental Study on Nano-Carbon Films as an Anti-Wear Protection for Drilling Tools
}

\author{
Camelia Popescu ${ }^{1}$, Daniel Cristea ${ }^{2}$ (D), Bogdan Bita $^{3}$, Rodica Cristescu ${ }^{1}$, Doina Craciun ${ }^{1}$, \\ Georgiana Diana Chioibasu ${ }^{1}$, Catalin Luculescu ${ }^{1}$, Irina Paun ${ }^{1}$, Liviu Duta ${ }^{1, *}$ \\ and Andrei C. Popescu 1,* \\ 1 National Institute for Lasers, Plasma and Radiation Physics (INFLPR), 077125 Magurele, Romania; \\ camelia.popescu@inflpr.ro (C.P.); rodica.cristescu@inflpr.ro (R.C.); doina.craciun@inflpr.ro (D.C.); \\ chioibasu.georgiana@inflpr.ro (G.D.C.); catalin.luculescu@inflpr.ro (C.L.); irina.paun@inflpr.ro (I.P.) \\ 2 Department of Materials Science, Faculty of Materials Science and Engineering, \\ Transilvania University of Brasov, 500068 Brasov, Romania; Daniel.cristea@unitbv.ro \\ 3 National Institute for Research and Development in Microtechnologies, RO-077190 Voluntari, Romania; \\ bita.bogdan@gmail.com \\ * Correspondence: liviu.duta@inflpr.ro (L.D.); andrei.popescu@inflpr.ro (A.C.P.); \\ Tel.: +40-21-457-4550 (ext. 2023) (L.D.); +40-21-457-4550 (ext. 2414) (A.C.P.)
}

Academic Editors: Chih-hung (Alex) Chang and Seung-Yeol Han

Received: 6 October 2017; Accepted: 7 December 2017; Published: 11 December 2017

\begin{abstract}
Carbon thin films of 50-100 nm thickness were synthesized by Pulsed Laser Deposition in vacuum at different laser fluences from 2 to $6 \mathrm{~J} / \mathrm{cm}^{2}$. The deposited films were characterized by Raman spectroscopy for compositional assessment, scanning electron microscopy for morphology/thickness evaluations, and X-ray reflectivity for density, thickness, and roughness determinations. The films were $\sim 100 \mathrm{~nm}$ thin, smooth, droplet-free, made of a-C:H type of diamond-like carbon. The mechanical properties of synthesized films were studied by nanoindentation and adhesion tests. The films that were obtained at low laser fluences $\left(2,3 \mathrm{~J} / \mathrm{cm}^{2}\right)$ had better mechanical properties as compared to those synthesized at higher fluences. The mean values of hardness were around $20 \mathrm{GPa}$, while the friction coefficient was 0.06 . The deposition conditions of carbon thin films that displayed the best mechanical properties were further used to coat commercial drills. Both uncoated and coated drills were tested on plates that were made of three types of steel: Stainless steel 304, general use AISI 572 Gr 65 steel (OL60), and AISI D3 tool steel (C120). All of the drill edges and tips were studied by optical and scanning electron microscopes. The coated samples were clearly found to be more resistant, and displayed less morphological defects than their uncoated counterparts when drilling stainless steel and OL60 plates. In the case of C120 steel, carbon coatings failed because of the high friction between drill and the metal plate resulting in tip edges blunting that occurred during processing.
\end{abstract}

Keywords: hard carbon films; protective coatings; pulsed laser deposition; drilling tools

\section{Introduction}

Diamond-like carbon (DLC) is a form of carbon that lacks order at large scale, but displays crystalline structure at the nanoscale level [1]. In the ideal case of single bonds between carbon atoms ( $\mathrm{sp}^{3}$ hybridization), the structure will have similar mechanical properties to those of diamond [2]. In general, DLC contains a mix of single and double bonds, and the ratio of $\mathrm{sp}^{3} / \mathrm{sp}^{2}$ hybridized carbon atoms dictates the mechanical behavior of this material [3,4].

Hard DLC is mainly used as protective coatings for metallic surfaces that have to withstand high friction, corrosion, and/or elevated temperatures [5-7]. Most commonly, DLC coatings are deposited by 
Chemical Vapor Deposition (CVD) [8,9] or magnetron sputtering [10], and have micrometer thickness 2-10 $\mu \mathrm{m}$ [11].

Generally, thicker DLC coatings have better mechanical properties than thinner films with the same structure, since the scratch and wear resistance are higher [12]. On the other hand, thick (micrometer) DLC coatings are susceptible to delamination and may require a buffer layer to enhance their adhesion to the metallic surface [6].

Some studies suggest that the thickness does not affect the mechanical behavior of films. Dorne et al. studied the wear behavior of Ti6Al4V coated with DLC coatings of various thicknesses within the range of $0.7-3.5 \mu \mathrm{m}$ and concluded that thickness does not play an important role in the wear resistance [13].

Pulsed Laser Deposition (PLD) [14] was one of the pioneering deposition techniques for the synthesis of DLC films with outstanding mechanical properties [15-17]. However, because of some serious disadvantages, such as small deposition area and slow deposition rate of PLD, other techniques are preferred for synthesis of DLC nowadays [18].

One of the novelty elements of this manuscript consists of the custom built translation and rotation robotic arm that is used for holding the substrate. This way, large areas such as $15 \mathrm{~cm}$ long drilling tools can be uniformly covered in a single step, and thus, one major inconvenience of PLD is eliminated. We exemplify this fact by uniformly coating twist drills with carbon thin films. Another novelty element is the find that even very thin (less than $100 \mathrm{~nm}$ ) DLC films synthesized by PLD can protect metallic tools during drilling. For the first time, such thin coatings were tested as protective layers for twist drills during processing of three types of steel as low carbon steel and two different hard tool steels.

\section{Materials and Methods}

\subsection{PLD Deposition}

Thin film synthesis procedure is given in refer. [3]. The carbon films were synthesized in vacuum of $2 \times 10^{-5} \mathrm{~Pa}$. In this work, the laser fluence was varied from 2 to $6 \mathrm{~J} / \mathrm{cm}^{2}$. The deposition parameters are summarized in Table 1.

Table 1. Experimental conditions for synthesis of carbon thin films by PLD.

\begin{tabular}{|c|c|c|c|c|c|c|c|c|}
\hline Target & Substrate & $\begin{array}{l}\text { Target-Substrate } \\
\text { Distance }(\mathrm{cm})\end{array}$ & $T\left({ }^{\circ} \mathrm{C}\right)$ & $\begin{array}{l}\text { Pressure } \\
(\mathrm{Pa})\end{array}$ & $\begin{array}{c}\text { Fluence } \\
\left(\mathrm{J} / \mathrm{cm}^{2}\right)\end{array}$ & $\begin{array}{c}\text { Energy } \\
(\mathrm{mJ})\end{array}$ & $\begin{array}{l}\text { No. of } \\
\text { Pulses }\end{array}$ & $\begin{array}{c}\text { Sample } \\
\text { Code }\end{array}$ \\
\hline $\begin{array}{l}\text { Carbon } \\
\text { graphite }\end{array}$ & $\mathrm{Si}(100)(20 \times 20) \mathrm{mm}^{2}$ & 5 & 200 & $2 \times 10^{-5}$ & $\begin{array}{l}2 \\
3 \\
4 \\
5 \\
6\end{array}$ & 500 & 5000 & $\begin{array}{l}\text { C1-F1 } \\
\text { C1-F2 } \\
\text { C1-F3 } \\
\text { C1-F4 } \\
\text { C1-F5 }\end{array}$ \\
\hline
\end{tabular}

For functional tests, commercial twist drills HSS Sprint (Alpen-Maykestag GmbH, Puch bei Hallein, Austria) of $6 \mathrm{~mm}$ diameter were used as substrates that were covered with carbon thin films. In order to reach the substrate temperature of $200{ }^{\circ} \mathrm{C}$, the drills heating was achieved by radiation from a small furnace placed in the immediate vicinity of the experimental setup. The drill temperature was measured and controlled using a chromel-alumel thermocouple (Type $K$ ).

Each set of tests was repeated five times in order to obtain statistically significant results.

\subsection{Characterization of Synthesized Structures}

The samples morphology was studied by Scanning Electron Microscopy (SEM) with a Nova Nanosem 630 instrument (FEI, Hillsboro, OR, USA). Cross-section investigations were conducted to assess film thickness. 
Both X-ray reflectivity (XRR) measurement curves and grazing incidence X-ray diffraction (GIXRD) patterns were acquired using a PANalytical X'Pert PRO MRD instrument (PANalytical, Almelo, The Netherlands) working with $\mathrm{CuK} \alpha$ radiation $(\lambda=1.5418 \AA$ ). For the GIXRD measurements, the incidence angle was set to $3^{\circ}$, step size at $0.03^{\circ}$, and time per step at $3 \mathrm{~s}$.

Raman spectra were obtained with a dispersive micro-Raman spectrometer (NRS-7200, JASCO, Tokyo, Japan) using a $532 \mathrm{~nm}$ laser excitation source. The laser light was focused on the films surface by means of a short working distance $100 \times$ objective lens with a numerical aperture (NA) $=0.9$ (Olympus, Tokyo, Japan) to a spot larger than $2 \mu \mathrm{m}$ in diameter. The nominal power of the laser was set to $5.5 \mathrm{~mW}$ and spectra were collected in a backscattering geometry in air. The spectral resolution was of $8 \mathrm{~cm}^{-1}$. Each spectrum was acquired for $30 \mathrm{~s}$ with 20 accumulations. All of the spectra were calibrated using pure polypropylene sample with a multipoint calibration procedure. The accuracy of calibrated spectra is under $\pm 1 \mathrm{~cm}^{-1}$. Some spectra were further smoothed using the Savitzky-Golay algorithm with 20 points.

The adhesion to the silicon substrates was assessed using a Micro Scratch Tester (CSM Instruments / Anton Paar, Peseux, Switzerland). Progressively increasing load linear scratches were traced, starting from $30 \mathrm{mN}$ up to $7000 \mathrm{mN}$, with a load rate of $5000 \mathrm{mN} / \mathrm{min}$. The end load was chosen in order to observe all three critical events on the coatings, namely the appearance of cracks, followed by partial delamination, and ultimately, the full delamination of the films. A Rockwel tip (100C 6 with a tip radius of $100 \mu \mathrm{m}$ ) was used. For each sample, five measurements were conducted in order to allow for a statistic analysis of the results.

Nanoindentations were performed using a NHT2 nanoindenter (CSM Instruments/Anton Paar, Peseux, Switzerland), with a diamond Berkovich tip. Because of the extremely thin film thickness, several decreasing loads were used, from $1.5 \mathrm{mN}$, down to $0.1 \mathrm{mN}$, in order to properly extract the mechanical properties (elastic modulus and indentation hardness). Furthermore, for such thin films, the thermal drift (expansions or contractions caused by variations in temperature in the measuring chain that can lead to errors) was counteracted by using a zirconium reference ring. This ring was put in contact with the sample surface, the displacement (penetration depth) being measured between the indenter and this reference ring, on the shortest possible path. For each applied load, 100 measurements were conducted, for statistical relevance.

A contact profilometer XP-2 (Ambios Technology, Santa Cruz, CA, USA) was used for investigating film thickness differences between various areas of a drill, because of possible shading generated by the irregular shape of the tool.

\subsection{Functional Tests}

For the functional tests, the drills pierced three metallic plates of $4 \mathrm{~mm}$ thickness. Stainless steel, steel for general use OL60, and tool steel C120 were chosen for these tests. In order to ensure the measurement reliability and repeatability, the drilling tests were conducted five times using five drills coated using the same deposition conditions for each type of steel. For comparison, uncoated drills were employed for piercing the metal plates. For the piercing process, an automated machine was used, with fixed position of the drill orthogonal onto the surface. The drilling speed was of $1 \mathrm{~m} / \mathrm{min}$ and no lubricant/coolant was used. In order to compare the wear surfaces, the samples were studied by optical and electron microscopes after drilling.

\section{Results}

\subsection{Films Morphology and Composition}

The films that were synthesized by PLD were smooth, lacking the typical droplets specific to PLD depositions [19,20] (Figure 1a). In case of carbon films, this morphology was expected, as spherical droplets are mainly caused by the liquid phase expulsion from the target surface during irradiation, as a result of blast waves, hydrodynamic instabilities, or subsurface melting [21]. Under both the pressure 
and temperature ranges used in this study, carbon sublimates without liquid phase, and consequently, without droplets onto the films surface. Some rare "bumps" were present on films surface that proved to be of graphitic nature when inspected by Raman Spectroscopy. They were most probably solid particles that were ripped from the target surface and further propelled towards the substrate during plasma plume expansion.

Films thickness was assessed by SEM study of cross-sections (Figure 1b) and XRR (Figure 2).
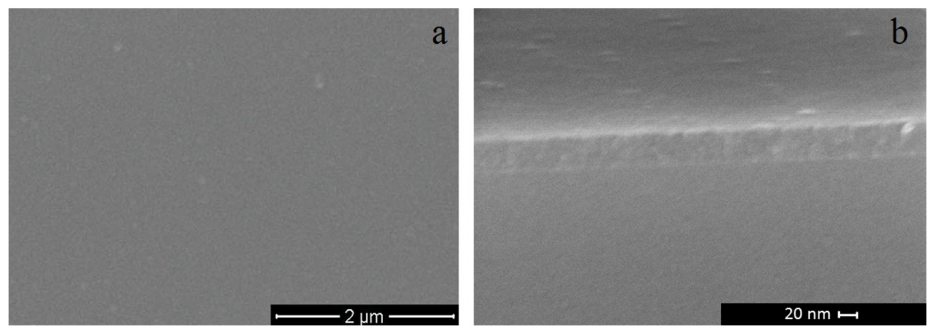

Figure 1. Typical SEM images of (a) surface morphology and (b) cross-section of C1-F2 carbon films synthesized by PLD at the deposition conditions from Table 1.

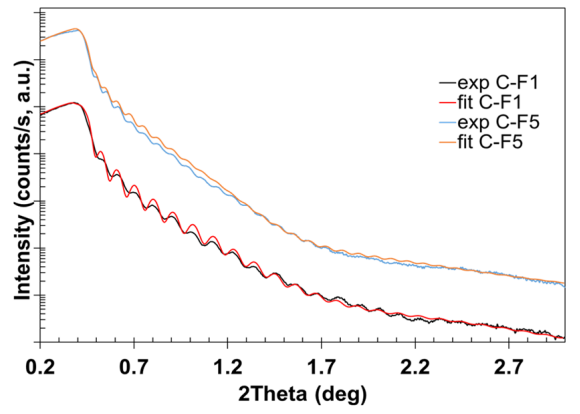

Figure 2. Typical XRR and simulation curves for C-F1 and C-F5 films synthesized at laser fluences of 2 and $6 \mathrm{~J} / \mathrm{cm}^{2}$, respectively.

Cross-sectional investigations revealed that the deposited films had a uniform thickness along the examined fracture. When deposited at the laser fluence of $2 \mathrm{~J} / \mathrm{cm}^{2}$, films were $50 \mathrm{~nm}$ thick, while their thickness was of $100 \mathrm{~nm}$ at $6 \mathrm{~J} / \mathrm{cm}^{2}$ laser fluence.

The films thickness measured from cross-sectional SEM images was compared to the data extracted from XRR patterns simulation (Figure 2). These simulations also provided information on both density and stratification of the PLD deposited carbon films. In the patterns on Figure 2, the blue color corresponds to the recorded data, while the red one is assigned to the simulated pattern. The results inferred from these measurements are presented in Table 2.

Table 2. Results obtained from simulation of XRR patterns in case of a set of carbon films synthesized by PLD in conditions depicted in Table 1.

\begin{tabular}{cccccc}
\hline Samples & Layer No. & Layer Type & Density $\left(\mathbf{g} / \mathbf{c m}^{3}\right)$ & Thickness $(\mathbf{n m})$ & Roughness $(\mathbf{n m})$ \\
\hline \multirow{2}{*}{ C1-F1 } & 2,0 & $\mathrm{C}$ & 1.8 & 72.7 & 0.4 \\
& 1,0 & $\mathrm{SiO}_{2}$ & 2.3 & 2 & 2 \\
C1-F2 & 2,0 & $\mathrm{C}$ & 1.9 & 60.8 & 0.2 \\
& 1,0 & $\mathrm{SiO}_{2}$ & 2.3 & 6 & 2.7 \\
C1-F3 & 2,0 & $\mathrm{C}$ & 2.1 & 55.2 & 0.4 \\
& 1,0 & $\mathrm{SiO}_{2}$ & 2.3 & 6.7 & 3 \\
C1-F4 & 2,0 & $\mathrm{C}$ & 2 & 58 & 0.3 \\
& 1,0 & $\mathrm{SiO}_{2}$ & 2.3 & 3.8 & 2 \\
C1-F5 & 2,0 & $\mathrm{C}$ & 2 & 96 & 0.2 \\
& 1,0 & $\mathrm{SiO}_{2}$ & 2.3 & 4 & 3 \\
\hline
\end{tabular}


The sample C1-F1, deposited at the lowest fluence, has the lowest density of $1.77 \mathrm{~g} / \mathrm{cm}^{3}$.

The samples C1-F2 are made of a single carbon layer, having the thickness of $\sim 60 \mathrm{~nm}$ and an estimated density of $1.8 \mathrm{~g} / \mathrm{cm}^{3}$. By increasing the laser fluence to $3 \mathrm{~J} / \mathrm{cm}^{2}$, a monolayer carbon film with a slightly increased density of $2 \mathrm{~g} / \mathrm{cm}^{3}$ and thickness of $\sim 55 \mathrm{~nm}$ was synthesized. Similar values of thickness and density were observed when increasing the laser fluence at $4 \mathrm{~J} / \mathrm{cm}^{2}$. The samples C1-F5 were the thickest $(96 \mathrm{~nm})$ and were formed of a single layer with density of $2 \mathrm{~g} / \mathrm{cm}^{3}$.

The type of bonds between the carbon atoms was assessed by Raman spectroscopy. Figure 3 displays a typical Raman spectrum together with its deconvolution acquired from a sample deposited at the laser fluence of $2 \mathrm{~J} / \mathrm{cm}^{2}$. The spectrum shows a broad peak between 900 and $1800 \mathrm{~cm}^{-1}$, which is in fact the overlap of the $D$ and $G$ bands characteristic to carbon films [22]: $D$ band is due to the breathing mode of graphitic hexagonal cells and is centered at $1378 \mathrm{~cm}^{-1}$, while the $G$ band stands for the $\mathrm{C}-\mathrm{C}$ stretch in double bonds and is centered at $1560 \mathrm{~cm}^{-1}$. According to the fit, there is a third band that is centered at $1230 \mathrm{~cm}^{-1}$, typically ascribed to nanocrystalline or "amorphous" diamond [23,24]. The values for the $\mathrm{sp}^{3}$ and $\mathrm{sp}^{2}$ content were assessed from the $\mathrm{sp}^{3} / \mathrm{sp}^{2}$ dependency on the $I_{\mathrm{D}} / I_{\mathrm{G}}$ ratio and frequency of $G$ band given in the works of Ferrari et al. [25] and Irmer et al. [26]. Based on the $G$ band peak centered at $1560 \mathrm{~cm}^{-1}$, and ratio $I_{\mathrm{D}} / I_{\mathrm{G}} \sim 1.3$, checking on the calibration curves in Figure 5 of [26] it seems that the films are a-C:H type of DLC, with a sp ${ }^{3} / \mathrm{sp}^{2}$ ratio of 0.33 , corresponding to $\sim 25 \% \mathrm{sp}^{3}$ coordinated carbon atoms and $\sim 75 \% \mathrm{sp}^{2}$.

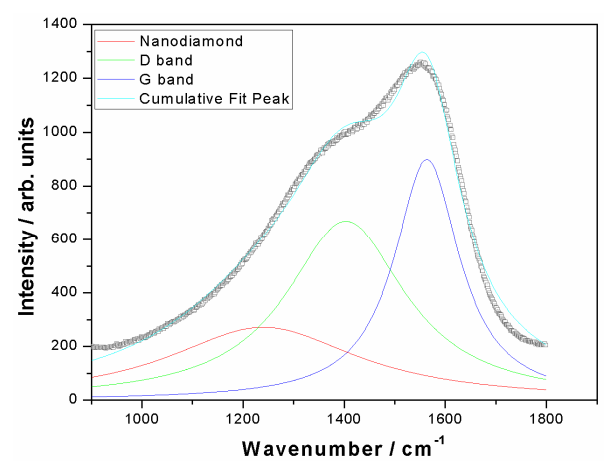

Figure 3. Typical Raman spectrum of carbon films synthesized by PLD in vacuum at $2 \mathrm{~J} / \mathrm{cm}^{2}$ laser fluence.

\subsection{Scratch Testing}

In theory, the increase of laser fluence is necessary for obtaining more energetic species in plasma that will usually result in thin films exhibiting increased hardness. In refer. [27] it is shown that the photon energy strongly influences the percentage of $\mathrm{sp}^{3}$ hybridized carbon in films. Figure $4 \mathrm{a}$ shows that films become more plastic as the laser fluence used for target ablation increases. In Figure 4a, there are marked areas where the film fails. The minimal loads that cause film failure are denoted in literature at LC1, LC2, and LC3 [28]. LC1 is the load that causes visible cracks in the film during indenter sliding, but the load is not enough to partially delaminate the film from the substrate. LC2 is the load that causes local delaminations of the film, while LC3 is the minimal load that removes more than $50 \%$ of the film from the substrate, on the scratch path. However, the film is considered compromised, starting with LC2.

Thus, films that are synthesized at 2 and $3 \mathrm{~J} / \mathrm{cm}^{2}$ exhibit partial delamination for a short while, followed by full delamination, while films that are synthesized at $4-6 \mathrm{~J} / \mathrm{cm}^{2}$ break suddenly, suggesting a more fragile behavior. The shape of the delaminated regions, for samples C1-F1 and C1-F2, suggests that rearward cracking occurs, behind the indenter, followed by through-thickness cracking and buckling/spallation, which is characteristic to hard coating/softer substrate combos. Figure $4 \mathrm{~b}$, represents the typical variation of the friction coefficient and the acoustic emission, as function of the applied load, in this particular case for sample C1-F3. One can notice a sudden increase in the friction 
coefficient, as soon as the LC3 load occurs. This means that the indenter starts to contact with the silicon substrate. The acoustic emission signal appears as a result of the cracking at the surface of the silicon substrate. Table 3 presents the mean forces that cause visible deformations for films, as well as the mean friction coefficient for each type of sample.

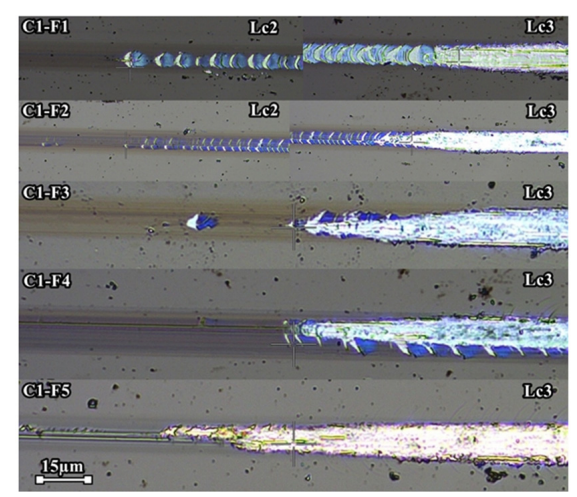

(a)

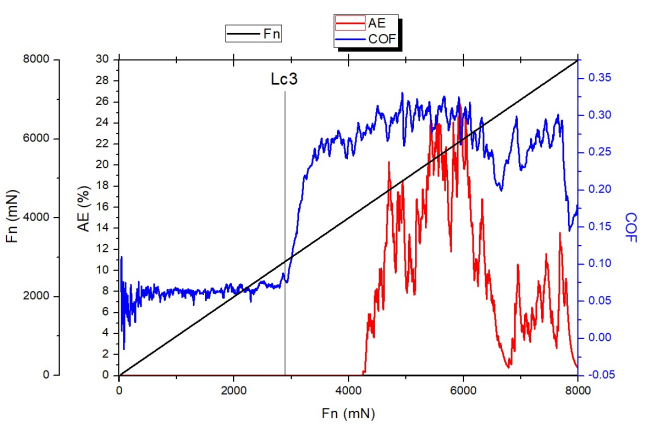

(b)

Figure 4. Areas of critical load (a), and the variation of friction coefficient and acoustic emissions as functions of the normal load (b).

Table 3. Mean values of the critical loads and computed friction coefficient.

\begin{tabular}{cccccc}
\hline Samples & LC2 $(\mathbf{m N})$ & StdDev & LC3 $(\mathbf{m N})$ & StdDev & Friction Coefficient $(\boldsymbol{\mu})$ \\
\hline C1-F1 & 3542 & 235.601 & 5436 & 203.5 & 0.06 \\
C1-F2 & 3025 & 316.429 & 3937 & 439.6 & 0.06 \\
C1-F3 & - & - & 3319 & 514.9 & 0.07 \\
C1-F4 & - & - & 3248 & 473 & 0.075 \\
C1-F5 & - & - & 3251 & 528 & 0.09 \\
\hline
\end{tabular}

In case of all the samples, excepting C1-F2, the friction coefficient was constant for the LC1 regime. Further on, the friction coefficient increased linearly with the applied load, from 0.06 up to 0.12.

Apparently, the films adherence decreased with the increase in laser fluence. A maximum value of adherence was identified for the samples C1-F1, the load necessary for breaking the films being of $5.4 \pm 0.2 \mathrm{~N}$. In the case of C1-F2 films, the necessary load for breaking the films decreased to $3.3 \pm 0.2$ N. For samples C1-F3, C1-F4, and C1-F5 no major differences of adherence were observed, the values of the critical load that breaks the films being of $\sim 3 \mathrm{~N}$. However, it must be specified that films synthesized at $2 \mathrm{~J} / \mathrm{cm}^{2}(\mathrm{C} 1-\mathrm{F} 1)$ are partially exfoliated starting from the load of $3.5 \pm 0.2 \mathrm{~N}$. Their total break occurs at $5.4 \pm 0.2 \mathrm{~N}$.

For C1-F2 films, the friction coefficient is the lowest (0.06). As a general note, the laser fluence does not seem to significantly influence the resulting films roughness. For C1-F2 up to C1-F5, the friction coefficient increases from 0.06 up to 0.09 .

Taking into consideration the adherence data, a conclusion could be that the films with the highest adherence as well as smoothest surface are obtained when laser fluences of $2-3 \mathrm{~J} / \mathrm{cm}^{2}$ are used for film synthesis.

\subsection{Nanoindentation Tests}

In order to achieve reliable nanoindentation measurements, for the case of the very thin layers, an analysis method based on the progressive decrease of the applied load in various points was elaborated. Thus, the starting load was of $1.5 \mathrm{mN}$. Furthermore, the samples were indented with decreasingly lower loads, towards $0.1 \mathrm{mN}$. It was observed that the hardness increased as the indenter pierced deeper into the film. The measurements continued until a sudden drop of the hardness values 
was observed. This drop was an indication that the silicon substrate influence on the measurement was total.

Extracting useful information from nanoindentation tests is not a clear-cut issue. The " $10 \%$ film thickness penetration depth" rule has no physical basis, as mentioned in [29]. As an example, it was demonstrated in [30] that in case of an aluminum film ( $3 \mu \mathrm{m}$ thickness) deposited on sapphire using a Berkovich tip, there was no substrate influence up to $70 \%$ of film thickness for the penetration depth. The results are highly dependent on the geometry of the indenter (Vickers, Berkovich, cube-corner, spherical), tip radius, tip sharpness/roundness when compared to the initial state, or elastoplastic response of the film/substrate system. For indentations with a pyramidal indenter, as it is the case herein, the indentation depth increases at the same rate as the area of contact. The ratio of penetration depth and film thickness, $h / t$, can be used as a scale parameter.

Figure 5a represents a typical load-displacement curve for thin films synthesized at various laser fluences. One can notice small jumps on the load curve, most probably because of the acquisition frequency. Figure $5 b, c$ exhibit the evolution of the mean hardness and elastic modulus as a function of the $\mathrm{h} / \mathrm{t}$ ratio, where $h$ is the penetration depth, and $\mathrm{t}$ is the thickness of the film. The characteristics of the substrate are clearly marked with a dashed line. For C1-F1 films, the obtained results were among the best. The hardness of these films was of $21 \pm 1.3 \mathrm{GPa}$. The increase of laser fluence to $3 \mathrm{~J} / \mathrm{cm}^{2}$ produced films with slightly lower hardness (18.5 $\pm 1.1 \mathrm{GPa})$. For C1-F3 samples, the lowest values of hardness $(16 \pm 0.8 \mathrm{GPa})$ were recorded. It is interesting to observe that the further increase of laser fluence determined an increase in film hardness. Thus, the C1-F4 had a hardness of $19 \pm 1.2 \mathrm{GPa}$, while and the C1-F5 had the highest recorded hardness (23.3 $\pm 1.8 \mathrm{GPa})$. It is worth noting that the carbon thin films had a density close to one of graphite $\left(2 \mathrm{vs} .2 .26 \mathrm{~g} / \mathrm{cm}^{3}\right)$, but the corresponding hardness was considerably much higher ( $H=23 \mathrm{GPa}$ vs. $0.3 \mathrm{GPa}$ [31]).

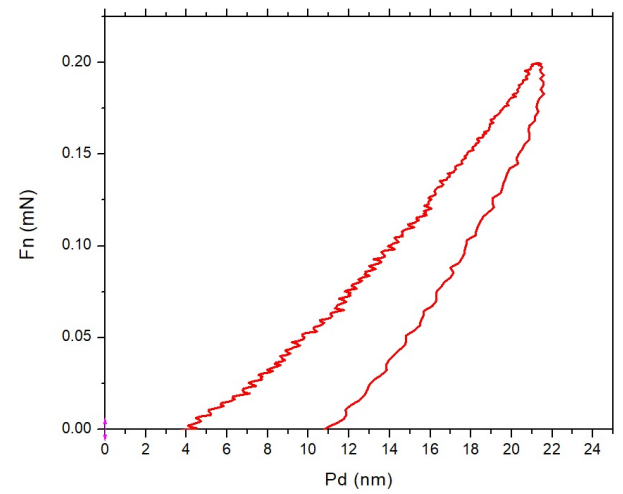

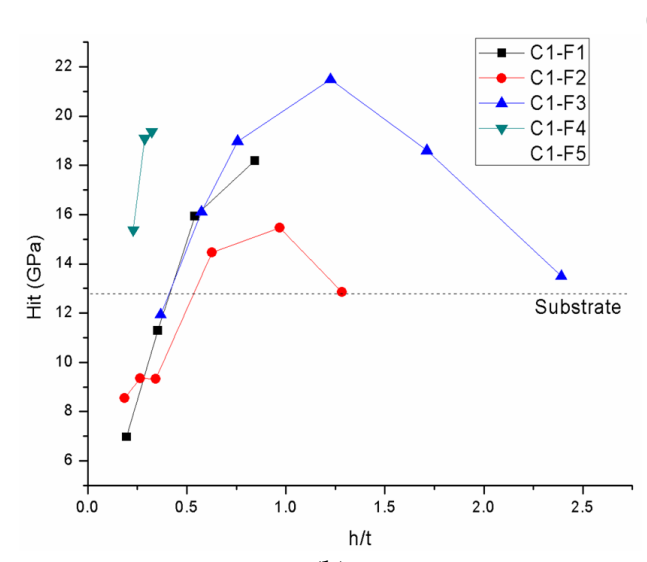

(b)

(a)

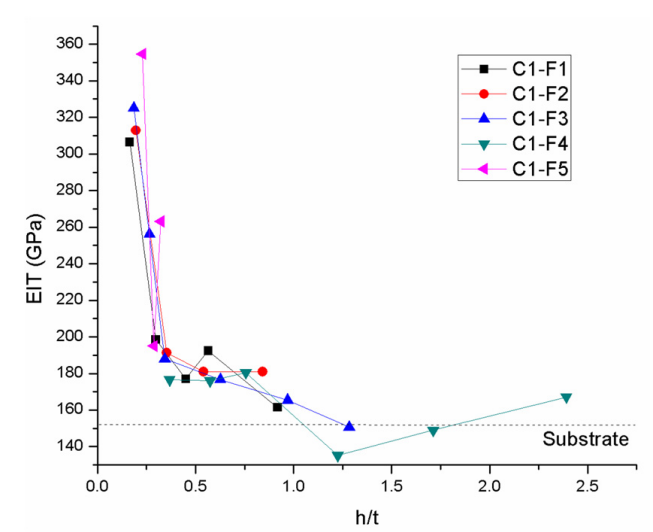

(c)

Figure 5. Typical load-displacement curve for carbon thin films synthesized by PLD in vacuum (a), mean hardness (b) and elastic modulus (c) as a function of applied load. 
As for the elastic modulus, for C1-F1 $E=232.8 \pm 22 \mathrm{GPa}, E=236.4 \pm 29.4 \mathrm{GPa}$ for C1-F2, while for C1-F3 its value was of $255.5 \pm 31.1 \mathrm{GPa}$. The C1-F4 samples that exhibited the weakest mechanical properties also had the lowest elastic modulus of upper layer: $164.5 \pm 8 \mathrm{GPa}$. Samples C1-F5 seem to have the highest value of the upper layer's elastic modulus, $341.4 \pm 32.6 \mathrm{GPa}$.

Both the hardness and elastic modulus fluctuations between films deposited at different laser fluences within the range of $2-6 \mathrm{~J} / \mathrm{cm}^{2}$ can be related to their structure. Studies have shown that the $\mathrm{sp}^{3} / \mathrm{sp}^{2}$ ratio is not linearly varying with the laser fluence [32-34]. For low fluence regimes $\left(2-3 \mathrm{~J} / \mathrm{cm}^{2}\right)$, the structure is mainly $\mathrm{sp}^{2}$ based, ordered at nanoscale in form of rings. In this case, $\mathrm{sp}^{3}$ bonds come from high energy $\mathrm{C}^{+}$ions in plasma that strike the film, causing the densification of the structure and transformation of $\mathrm{sp}^{2}$ bonds into tetrahedral $\mathrm{sp}^{3}$ bonds. At higher laser fluences, the $\mathrm{sp}^{2}$ bonds in form of rings, are broken and form $\mathrm{sp}^{2}$ chains and clusters. This is characteristic for a maximum state of disorder. Therefore, it is possible that the mechanical properties of such structures to be lower. At $5 \mathrm{~J} / \mathrm{cm}^{2}$, which [34] considers it as threshold, the disordered $\mathrm{sp}^{2}$ phase starts to transform in tetrahedral bonded amorphous structure. The larger percentage of $\mathrm{sp}^{3}$ should be the main reason for better values of hardness and elastic modulus in case of such films.

\subsection{Functional Tests}

Due to their mechanical performances at scratch and nanoindentation tests, twisted drills were coated with thin carbon films synthesized using the experimental conditions applied for C1-F1 samples. One could argue that samples C1-F6 had slightly better mechanical properties, but it was considered that these marginal increases do not justify the energy consumption that is required for passing from 2 to $6 \mathrm{~J} / \mathrm{cm}^{2}$. The thin films that coat the drills modified their visual aspect. Figure 6 depicts commercial drills, two deposited with a thin carbon film that gives them a gray metallic color, and two uncoated ones, just taken out of their commercial package that are much darker in color.

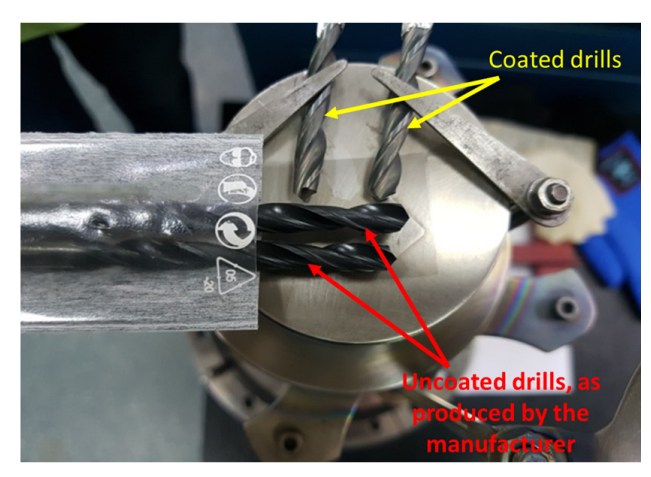

Figure 6. Photograph of carbon thin film covered drills (gray) and uncoated drills (black) presented for comparison, immediately after deposition/unpacking.

Figure 7a represents an optical image of a drill tip coated with a carbon thin film. The deposition was uniform and there were no uncoated areas. No film cracks or delaminations were identified at the edges of drill. Figure $7 \mathrm{~b}$ presents a darker, deposited area and an uncoated area that was covered with a metallic aluminum foil during the deposition process.

Thickness of films that were deposited on the drill should be similar to the thickness of films grown on the Si substrate, as the deposition conditions are the same. Coating thickness differences might be possible due to the drill irregular shape. However, because the carbon films are very thin, differences should be in the range of tens of $\mathrm{nm}$. In order to check this hypothesis, contact profilometry was used to investigate height differences on a straight direction along the coated drill. The tip area, a twisted edge and a flank were verified. Arithmetical mean height $\left(R_{\mathrm{a}}\right)$ roughness differences in the $\mathrm{nm}$ range were assessed between measured points: $R_{\mathrm{a}}=15 \mathrm{~nm}$ for the tip area, $20 \mathrm{~nm}$ for the edge and $16 \mathrm{~nm}$ for the flank. 

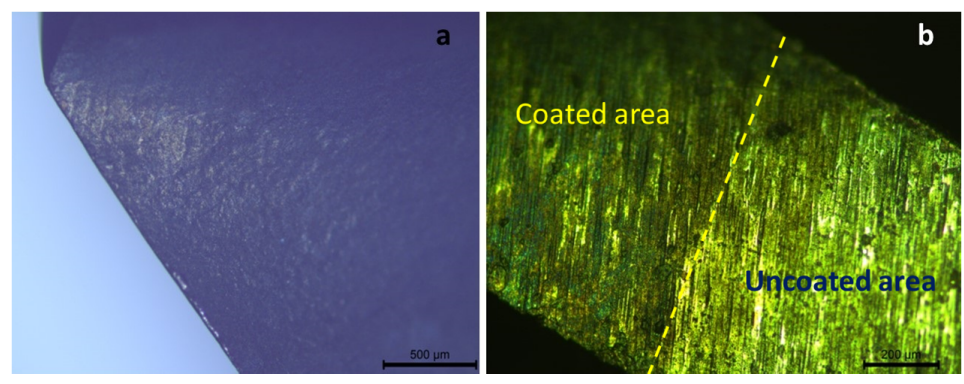

Figure 7. Optical microscopy images corresponding to carbon thin film deposition on metal piercing drills: (a) drill tip and (b) interface between coated and uncoated areas.

Figure 8 displays optical microscopy images of uncoated (Figure 8a,c,e) and coated (Figure 8b,d,f) drill tips after piercing $4 \mathrm{~mm}$ thick metal plates of stainless steel, OL60 or C120 with a drilling speed of $1 \mathrm{~m} / \mathrm{min}$. Optical microscopy images did not show major differences in the wear of the uncoated and coated drill bodies. There were visible dissimilarities at the edges only. Thus, in the case of stainless steel (with a very low carbon content of $0.1 \%$ ) that is softer than OL60 or C120, only small erosions and slight deformations of the drill edges were noticed after drilling processing (Figure 8a). However, the carbon films perfectly protected the drill tip and no delamination or exfoliations were observed, while the edges remained sharp after utilization, without traces of erosion (Figure $8 \mathbf{b}$ ). In case of OL60 steel, a quality carbon steel with $0.6 \%$, much harder and brittle than stainless steel, the edges displayed more pronounced differences. Thus, the uncoated edges experienced serious deformations during drilling, which were easily visible at the optical microscope (Figure 8c), while the coated ones remained sharp, without visible deformations. The films have remained adherent to the drill surface after piercing and have not displayed exfoliations (Figure 8d). Tool steel C120, with a high content of carbon (1.2\%) also induced the wear of uncoated edges during the drilling procedure, causing deformations (Figure 8e). The carbon films resisted during piercing this material and protected the edges of the drill. No signs of wear, breaks, or deformations of the edges were identified.

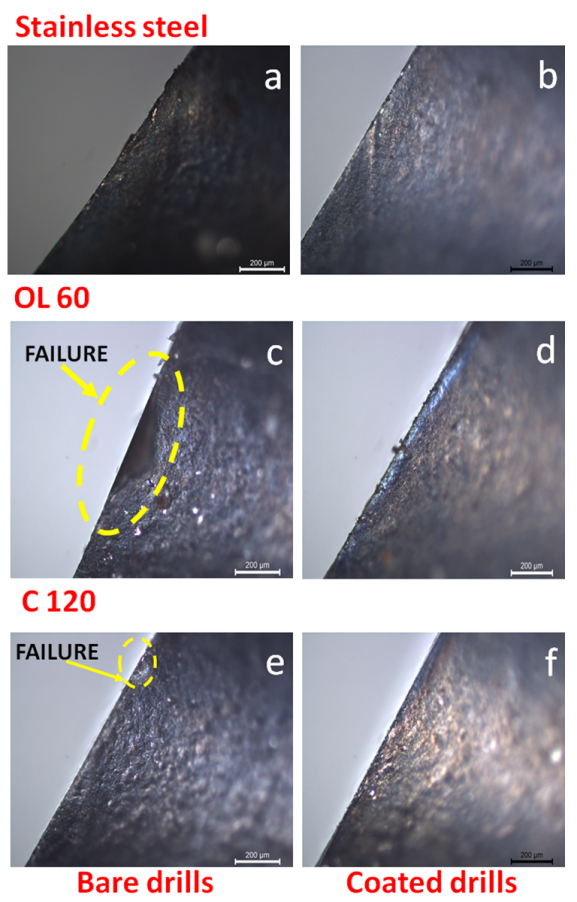

Figure 8. Optical microscopy images corresponding to edges of uncoated $(\mathbf{a}, \mathbf{c}, \mathbf{e})$ and carbon film coated $(\mathbf{b}, \mathbf{d}, \mathbf{f})$ drills after piercing of stainless steel, OL60 and C120. 
Both drill tips and flanks were further studied by SEM. Figure 9 shows in the left column uncoated drill tips after drilling of various steel samples, while the right column displays coated tips at the end of the drilling operation. Figure 9a presents a coated untested drill, to be used as control for subsequent comparisons.
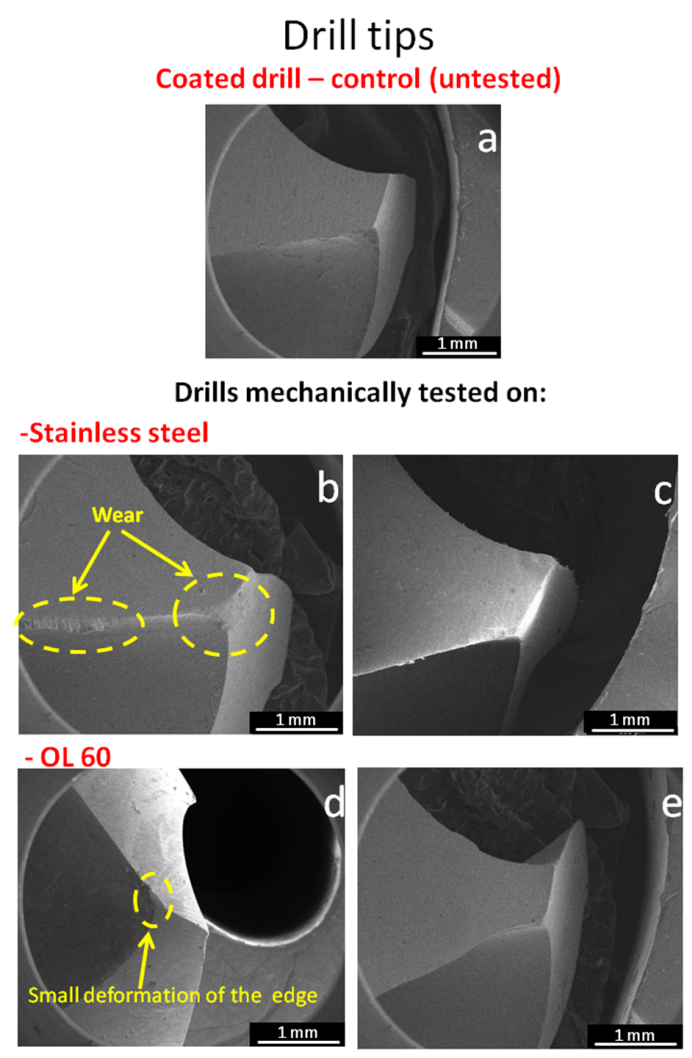

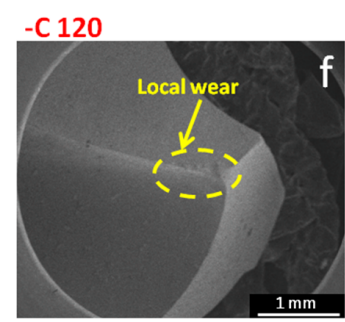

Bare drills

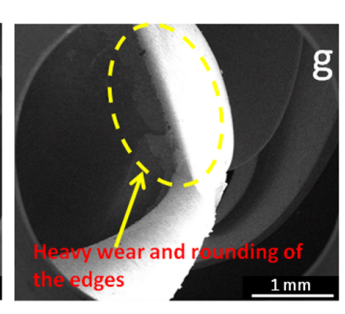

Coated drills

Figure 9. SEM images of an untested coated drill used as control (a), and of uncoated $(\mathbf{b}, \mathbf{d}, \mathbf{f})$ and coated $(\mathbf{c}, \mathbf{e}, \mathbf{g})$ drills after piercing of $4 \mathrm{~mm}$ thick plates of stainless steel, OL60 and C120.

After drilling the stainless steel metal plate, the uncoated drill displayed evident wear of the tip and flanks (Figure 9b). It is interesting to note that the wear is not homogeneous and not all edges were similarly worn during processing. This could be probably caused by either inhomogeneities in the material or small microscopic defects at the drills edges that became failure centers. No obvious worn areas were identified when the same drilling operation using carbon coated drills was performed (Figure 9b).

The uncoated drills that processed OL60 plates displayed significantly lower traces of wear in the tip area (Figure 9d). Only slight, isolated edge flattening was observed by SEM. In this case the drill flanks seem to be the most affected, as shown by optical microscopy images in Figure 8. The carbon coated tool tip seemed unaffected after drilling the OL60 plate (Figure 9e).

An obvious adverse effect was noticed at the tip level of the coated drills after processing the $\mathrm{C} 120$ plate; while, the uncoated sample displayed only relatively minor wear on the edges adjacent to the 
tip (Figure 9f), the coated samples were heavily affected by processing the C120 steel (Figure 9g). SEM inspection of tip indicated a blunting of the tip edges simultaneously to heavy wear marks. The SEM images were affected by charging, probably a sign of a large scale oxidation. This fact leads to the supposition of both heavy friction and high temperatures reached by the drill during processing. In this particular case, the carbon thin film seems to negatively affect the friction between the drill and C120 steel. However, this seems to happen only at the tip level, as the edges seem unaffected by wear, as seen in Figure 8f. It can be concluded that drills that are coated with carbon thin films are unsuitable for machining C120 steel in dry conditions, as they shorten the service life of drill.

When putting a type $\mathrm{K}$ thermocouple in contact with the drill tip immediately after piercing the steel plates, a maximum value of temperature was recorded. Table 4 lists these values for both uncoated and coated drills after processing $4 \mathrm{~mm}$ thick plates of stainless steel, OL60 and C120. The maximum value of recorded temperature between five identical drills that process the same type of steel fluctuated by $\pm 1^{\circ} \mathrm{C}$.

The temperature of drill tip before processing was of $23^{\circ} \mathrm{C}$.

The recorded drill tip temperatures indicate that stainless steel produces slightly higher temperatures of the uncoated drill during processing, as compared to carbon steels. Moreover, by examining Figure $9 b$, one can notice significantly higher wear as compared to carbon steels. This is the most probably associated with work hardening. Coated drills had a higher temperature than the uncoated ones after processing C120 steels, indicating that higher frictions are involved when the carbon layer is applied.

Table 4. Maximum value of temperature at drill tip level, recorded immediately after piercing a $4 \mathrm{~mm}$ thick steel plate.

\begin{tabular}{cccc}
\hline Surface Condition & Stainless Steel & OL60 & C120 \\
\hline Uncoated drill tips temperature $\left({ }^{\circ} \mathrm{C}\right)$ & 72 & 68 & 69 \\
Coated drills tips temperature $\left({ }^{\circ} \mathrm{C}\right)$ & 63 & 60 & 78 \\
\hline
\end{tabular}

\section{Discussion}

It has been shown that the deposition of carbon thin films by PLD is strongly influenced by the substrate temperature. Salah et al. [35] tested the morphology and roughness of DLC films that were synthesized between $100-500{ }^{\circ} \mathrm{C}$, and observed that the increase of temperature determines the transformation of film inherent nanostructures of into clusters. This phenomenon determines a gradual roughening of films, graphitization, and high values of the friction coefficient. In the case of carbon film synthesis reported in this manuscript, $100{ }^{\circ} \mathrm{C}$ was not sufficient for obtaining adherent films. $200{ }^{\circ} \mathrm{C}$ was the minimum temperature for obtaining adherent films with hardness values between 20-30 GPa. Increasing the temperature beyond $200^{\circ} \mathrm{C}$ caused a decrease in the mechanical properties of the films.

In general, PLD carbon film thickness is in the range of hundreds of nm. As examples, Salah et al. [35] report a film thickness in the range of $270 \mathrm{~nm}$, Gayathri et al. [36] obtained $500 \mathrm{~nm}$ thick films, Constantinou et al. [37] synthesized $125 \mathrm{~nm}$ films, and in this work, $100 \mathrm{~nm}$ thin films are reported.

The protective carbon film thickness in case of industrial coating of mechanical tools is, in general, at the micron level. In the case of mechanical applications, the chosen method for coating drills is the chemical vapor deposition. Some studies show that the increase of coating thickness provides a longer tool life. Qin et al. [12] synthesized carbon coatings of 4, 17, and $29 \mu \mathrm{m}$, respectively, and drilled a composite material A359/SiC-20p. They observed that abrasive wear resistance was indeed increased for films of $17 \mu \mathrm{m}$ thickness, as compared to $4 \mu \mathrm{m}$ thick ones, but found no significant evidence between 17 and $29 \mu \mathrm{m}$ films. Failure mainly occurred at the corner between two cutting edges. In case of the present research, it was found that uncoated drills fail at the edges and the tip shows wear marks 
for all of the processed materials. Silva et al. [5] showed that failure of protective carbon coatings occurs foremost in these areas. They used carbon coated drills for piercing 1800 holes on a SAE 323 aluminum alloy. After processing, the drills were studied by electron microscopy, revealing that the films were ripped mostly at the cutting edges of the drill. The tip was the most affected with the largest area of delaminated film and showing crater wear on the edges. In their case, wear seems to mostly be at the edges level, while in the case of the present research, the tip itself is blunted.

In order to test if the carbon is suitable as protective coating for drills, Heinemann et al. [38] used $\mathrm{a}-\mathrm{C}: \mathrm{H}$ type of carbon and processed a plain carbon steel. The general conclusion of the study was that DLC coated drills are suitable for machining thick pieces due to their capability to easier evacuate the resulting chip by means of a low friction coefficient, as compared to uncoated tools. However, the lifetime of the tools has not increased. The quality of the deposition is heavily affecting the lifetime of the tool. In case of some drills, the lifetime of the drill decreased by $15 \%$ in the case of rough, nodular DLC depositions. For the present research, even though the carbon coating is $100 \mathrm{~nm}$ thin only, it seems that for the cases of stainless and OL60 steels, it ensures protection for the edges and tips. For explaining the failure in case of $\mathrm{C} 120$ steel, we advance the following hypothesis: Being the hardest studied steel from our set due to the highest carbon content, it requires a more prolonged interaction with the drill and higher processing temperatures due to friction. At these temperatures, metal parts can become adherent to the drill tip or edges, they continue to accumulate during processing and form a rough layer that significantly increases friction. Similar failure mechanisms were proposed by Kao et al. [39] in case of drills that were coated with Cr-C:H coatings.

\section{Conclusions}

Thin carbon films were synthesized by Pulsed Laser Deposition on Si substrates at laser fluences ranging between 2 and $6 \mathrm{~J} / \mathrm{cm}^{2}$. The films were uniformly thick and their surface was smooth and free of droplets. Only some rare bumps were observed by scanning electron microscopy and were identified by Raman spectroscopy to be of graphitic nature, probably caused by the solid phase expulsion from the graphite target.

The films were a-C:H type of diamond-like carbon. The hardest films had density close to that of graphite $\left(\sim 2 \mathrm{~g} / \mathrm{cm}^{3}\right)$, but 20 times harder.

The best mechanical properties were obtained for films synthesized at low laser fluencies, i.e., 2 and $3 \mathrm{~J} / \mathrm{cm}^{2}$. This ensured hardness value of $\sim 20 \mathrm{GPa}$, elastic modulus of $\sim 230 \mathrm{GPa}$, and friction coefficients of $\sim 0.06$.

The mechanical behavior of films in real work conditions was tested by coating with carbon films commercial untreated drills. A robotic arm was used for ensuring translation and rotation of samples in order to coat uniformly the $10 \mathrm{~cm}$ long drills.

Depositions were homogeneous and the films resisted on the tips/edges of the drills that are the most susceptible to either exfoliation or breaking. Both uncoated and coated drills were tested on plates that were made of stainless steel, OL60 and C120, respectively. In all cases, either the tip or the edges of the uncoated drills suffered from breaks or deformations easily distinguishable by optical or scanning electron microscopies. The drill edges were prone to less defects following processing, when being coated with the carbon thin films. In the case of tips, carbon films protected the drill when piercing the stainless steel and OL60 plates, presenting considerable less wear, but when processing C120 steel, heavy wear together with flanks blunting were observed, suggesting that carbon coated drills were not suitable for processing this type of steel.

Acknowledgments: The authors acknowledge the financial support of the National Program PN 16 47-LAPLAS IV. Camelia Popescu, Liviu Duta and Andrei C. Popescu acknowledge the support of the Romanian National Authority for Scientific Research and Innovation, CNCS-UEFISCDI, under the projects no. PN-II-RU-TE-2014-4-1570 (Contract no. 108/2015) and PN-III-P2-2.1-PED-2016-1309 (Contract no. 241/2017). Daniel Cristea acknowledges the structural funds project PRO-DD (POS-CCE, O.2.2.1., ID 123, SMIS 2637, ctr. No 11/2009) for providing the infrastructure for adhesion and nanoindentation tests. 
Author Contributions: Andrei C. Popescu and Liviu Duta conceived and supervised the PLD experiments and conducted the functional tests. Camelia Popescu analyzed and compiled the data and wrote the manuscript. Rodica Cristescu and Georgiana Diana Chioibasu conducted the PLD experiments. Doina Craciun was in charge of XRD experiments, Bogdan Bita analyzed the samples by SEM, Daniel Cristea designed and conducted the nanoindentation tests, while Irina Paun and Catalin Luculescu were in charge of Raman analyses.

Conflicts of Interest: The authors declare no conflict of interest. The founding sponsors had no role in the design of the study; in the collection, analyses, or interpretation of data; in the writing of the manuscript, and in the decision to publish the results.

\section{References}

1. Robertson, J. Diamond-like amorphous carbon. Mater. Sci. Eng. R 2002, 37, 129-281. [CrossRef]

2. Dai, W.; Liu, J.; Geng, D.; Guo, P.; Zheng, J.; Wang, Q. Microstructure and property of diamond-like carbon films with $\mathrm{Al}$ and $\mathrm{Cr}$ co-doping deposited using a hybrid beams system. Appl. Surf. Sci. 2016, 388, 503-509. [CrossRef]

3. Popescu, A.C.; Stan, G.E.; Duta, L.; Nita, C.; Popescu, C.; Surdu, V.A.; Husanu, M.A.; Bita, B.; Ghisleni, R.; Himcinschi, C.; et al. The role of ambient gas and pressure on the structuring of hard diamond-like carbon films synthesized by pulsed laser deposition. Materials 2015, 8, 3284-3305. [CrossRef]

4. Suschke, K.; Hubner, R.; Murmu, P.P.; Gupta, P.; Futter, J.; Markwitz, A. High energy radial deposition of diamond-like carbon coatings. Coatings 2015, 5, 326-337. [CrossRef]

5. Silva, W.M.; Jesus, L.M.; Carneiro, J.R.; Souza, P.S.; Martins, P.S.; Trava-Airoldi, V.J. Performance of carbide tools coated with DLC in the drilling of SAE 323 aluminum alloy. Surf. Coat. Technol. 2015, 284, 404-409. [CrossRef]

6. Bhowmick, S.; Banerji, A.; Alpas, A.T. Tribological behavior of Al-6.5\%, $-12 \%,-18.5 \%$ Si alloys during machining using CVD diamond and DLC coated tools. Surf. Coat. Technol. 2015, 284, 353-364. [CrossRef]

7. Ciniero, A.; Le Rouzic, J.; Reddyhoff, T. The use of triboemission imaging and charge measurements to study DLC coating failure. Coatings 2017, 7, 129. [CrossRef]

8. Nakazawa, H.; Kamata, R.; Okuno, S. Deposition of silicon-doped diamond-like carbon films by plasma-enhanced chemical vapor deposition using an intermittent supply of organosilane. Diam. Relat. Mater. 2015, 51, 7-13. [CrossRef]

9. Popa, A.C.; Stan, G.E.; Husanu, M.A.; Pasuk, I.; Popescu, I.D.; Popescu, A.C.; Mihailescu, I.N. Multi-layer haemocompatible diamond-like carbon coatings obtained by combined radio frequency plasma enhanced chemical vapor deposition and magnetron sputtering. J. Mater. Sci. Mater. Med. 2013, 24, 2695-2707. [CrossRef] [PubMed]

10. Wiatrowski, A.; Kijaszek, W.; Posadowski, W.M.; Oleszkiewicz, W.; Jadczak, J.; Kunicki, P. Deposition of diamond-like carbon thin films by the high power impulse magnetron sputtering method. Diam. Relat. Mater. 2017, 72, 71-76. [CrossRef]

11. Bewilogua, K.; Hofmann, D. History of diamond-like carbon films-From first experiments to worldwide applications. Surf. Coat. Technol. 2014, 242, 214-225. [CrossRef]

12. Qin, F.; Chou, Y.K.; Nolen, D.; Thompson, R.G. Coating thickness effects on diamond coated cutting tools. Surf. Coat. Technol. 2009, 204, 1056-1060. [CrossRef]

13. Dorner, A.; Schürer, C.; Reisel, G.; Irmer, G.; Seidel, O.; Müller, E. Diamond-like carbon-coated Ti6A14V: Influence of the coating thickness on the structure and the abrasive wear resistance. Wear 2001, 249, 489-497. [CrossRef]

14. Yang, D. Applications of Laser Ablation-Thin Film Deposition, Nanomaterial Synthesis and Surface Modification; InTech: Rijeka, Croatia, 2016; p. 426.

15. Rau, J.V.; Teghil, R.; De Bonis, A.; Generosi, A.; Paci, B.; Generosi, R.; Fosca, M.; Ferro, D.; Rossi Albertini, V.; Chilingarov, N.S. Pulsed laser deposition of hard and superhard carbon thin films from C60 targets. Diam. Relat. Mater. 2010, 19, 7-14. [CrossRef]

16. Voevodin, A.A.; Donley, M.S.; Zabinski, J.S. Pulsed laser deposition of diamond-like carbon wear protective coatings: A review. Surf. Coat. Technol. 1997, 92, 42-49. [CrossRef]

17. Qian, F.; Craciun, V.; Singh, R.K.; Dutta, S.D.; Pronko, P.P. High intensity femtosecond laser deposition of diamond-like carbon thin films. J. Appl. Phys. 1999, 86, 2281-2290. [CrossRef] 
18. Eason, R. Pulsed Laser Deposition of Thin Films: Applications-Led Growth of Functional Materials; Wiley: New York, NY, USA, 2007; p. 682.

19. Hino, T.; Mustofa, S.; Nishida, M.; Araki, T. Reduction of droplet of tantalum oxide using double slit in pulsed laser deposition. Vacuum 2003, 70, 47-52. [CrossRef]

20. Craciun, V.; Craciun, D. Evidence for volume boiling during laser ablation of single crystalline targets. Appl. Surf. Sci. 1999, 138, 218-223. [CrossRef]

21. Lescoute, E.; Hallo, L.; Hébert, D.; Chimier, B.; Etchessahar, B.; Tikhonchuk, V.T.; Chevalier, J.M.; Combis, P. Experimental observations and modeling of nanoparticle formation in laser-produced expanding plasma. Phys. Plasma 2008, 15, 063507. [CrossRef]

22. Hu, A.; Rybachuk, M.; Lu, Q.B.; Duley, W.W. Femtosecond pulsed laser deposition and optical properties of diamond-like amorphous carbon films embedded with SP-bonded carbon chains. Diam. Relat. Mater. 2008, 17, 1643-1646. [CrossRef]

23. De Barros, M.I.; Vandenbulcke, L. Plasma-assisted chemical vapor deposition process for depositing smooth diamond coatings on titanium alloys at moderate temperature. Diam. Relat. Mater. 2000, 9, 1862-1866. [CrossRef]

24. Morshed, M.M.; McNamara, B.P.; Cameron, D.C.; Hashmi, M.S.J. Stress and adhesion in DLC coatings on 316L stainless steel deposited by a neutral beam source. J. Mater. Process. Technol. 2003, 143, 922-926. [CrossRef]

25. Ferrari, A.C.; Robertson, J. Interpretation of Raman spectra of disordered and amorphous carbon. Phys. Rev. B 2000, 61, 14095-14107. [CrossRef]

26. Irmer, G.; Dorner-Reisel, A. Micro-Raman studies on DLC coatings. Adv. Eng. Mater. 2005, 7, 694-705. [CrossRef]

27. McCann, R.; Roy, S.S.; Papakonstantinou, P.; McLaughlin, J.A.; Ray, S.C. Spectroscopic analysis of $a-C$ and $a-\mathrm{CN}_{x}$ films prepared by ultrafast high repetition rate pulsed laser deposition. J. Appl. Phys. 2005, 97, 073522. [CrossRef]

28. Misra, R.D.K.; Zhang, Z.; Jia, Z.; Surya, P.V.; Somani, M.C.; Karjalainen, L.P. Nanomechanical insights into the deformation behavior of austenitic alloys with different stacking fault energies and austenitic stability. Mater. Sci. Eng. A 2011, 528, 6958-6963. [CrossRef]

29. Fischer-Cripps, A.C. Nanoindentation, 3rd ed.; Springer: Berlin, Germany, 2011; p. 279.

30. Hay, J.L.; O'Hern, M.E.; Oliver, W.C. The importance of contact radius for substrate independent property measurement of thin films. Mater. Res. Soc. Symp. Proc. 1998, 522, 27-32. [CrossRef]

31. Carbon-Graphite Materials. Available online: https://www.azom.com/properties.aspx?ArticleID=516 (accessed on 3 October 2017).

32. Bonelli, M.; Fioravanti, A.P.; Miotello, A.; Ossi, P.M. Structural and mechanical properties of Ta-C films grown by pulsed laser deposition. Europhys. Lett. 2000, 50, 501-506. [CrossRef]

33. Bonelli, M.; Ferrari, A.C.; Fioravanti, A.P.; Bassi, A.L.; Miotello, A.; Ossi, P.M. Structure and mechanical properties of low stress tetrahedral amorphous carbon films prepared by pulsed laser deposition. Eur. Phys. J. B 2002, 25, 269-280. [CrossRef]

34. Liu, X.; Metcalf, T.H.; Mosaner, P.; Miotello, A. Laser fluence dependence of the elastic properties of diamond-like carbon films prepared by pulsed-laser deposition. Appl. Surf. Sci. 2007, 253, 6480-6486. [CrossRef]

35. Salah, N.; Alshahrie, A.; Iqbal, J.; Hasan, P.M.Z.; Abdel-wahab, M.S. Tribological behavior of diamond-like carbon thin films deposited by the pulse laser technique at different substrate temperatures. Tribol. Int. 2016, 103, 274-280. [CrossRef]

36. Gayathri, S.; Kumar, N.; Krishnan, R.; Ravindran, T.R.; Dash, S.; Tyagi, A.K.; Sridharan, M. Influence of Cr content on the micro-structural and tribological properties of PLD grown nanocomposite DLC-Cr thin films. Mater. Chem. Phys. 2015, 167, 194-200. [CrossRef]

37. Constantinou, M.; Pervolaraki, M.; Koutsokeras, M.; Prouskas, C.; Patsalas, P.; Kelires, P.; Giapintzakis, J.; Constantinides, G. Enhancing the nanoscratch resistance of pulsed laser deposited DLC films through molybdenum-doping. Surf. Coat. Tehnol. 2015, 330, 185-195. [CrossRef] 
38. Heinemann, R.K.; Hinduja, S. Investigating the feasibility of DLC-coated twist drills in deep-hole drilling. Int. J. Adv. Manuf. Technol. 2009, 44, 862-869. [CrossRef]

39. Kao, W.H.; Su, Y.L.; Yao, S.H. Tribological property and drilling application of Ti-C:H and Cr-C:H coatings on high-speed steel substrates. Vacuum 2006, 80, 604-614. [CrossRef] 